\title{
Cancer/Testis Antigen
}

National Cancer Institute

\section{Source}

National Cancer Institute. Cancer/Testis Antigen. NCI Thesaurus. Code C107566.

A family of immunogenic proteins that are found in a wide variety of tumors but are not expressed in adult somatic cells. Non-pathologic expression of these proteins is restricted to male germ cells. 